\title{
Antecedents of e-marketing orientation in SMEs: An exploratory study
}

\author{
Research-in-Progress
}

\author{
Abdel Monim Shaltoni \\ Alfaisal University \\ ashaltoni@alfaisal.edu
}

\begin{abstract}
An organizations e-marketing orientation (EMO) reflects beliefs and behaviors towards adopting e-marketing and consequently shapes involvement in cyberspace. This effort sheds more light on SMEs adoption of e-marketing through examining EMO and its antecedents in a structural model that specified EMO as a second order formative that consists of three reflective indicators. Based on a survey of SMEs in different sectors and countries, EMO philosophical and behavioral components were validated. It was also found that the degree of EMO is primarily affected by technological contexts factors such as perceived relative advantage and compatibility.
\end{abstract}

\section{Keywords}

E-marketing orientation; technological context, external pressure, SMEs, formative construct 


\section{Background}

It remains an everyday experience that users of the Internet will click on a website for one SME and find advanced online services whereas they might visit another company website only to find a simple description of their products and provision of their contacts. These and other related differences can be measured objectively via SMEs respective degrees of e-marketing orientation (hereinafter referred to as EMO). SMEs are widely recognized as being central to economic growth and, from a public policy perspective, it is important to any society that they take full advantage of any benefits offered by e-marketing. The main aim of this paper is to understand emarketing adoption in SMEs through analyzing and validating EMO as a high order formative construct.

Inspired by the two classical views of market orientation, Kohli and Jaworskis' behavioral (1990) perspective versus Narver and Slater's (1990) philosophical perspective, EMO was conceptualized as a synthesis of the behaviors towards the adoption of e-marketing and the concurrent organizational business philosophy (Shaltoni and West 2010). The rationale here is that behaviors alone are not enough to understand organizational orientations because philosophies play a major role in shaping such orientations (Avlonitis and Gounaris 1999). The philosophical component of EMO reflects organizational beliefs and attitudes towards e-marketing, which finds form in the emphasis placed on e-marketing by those with the authority to determine the extent to which it is adopted. Turning to the behavioral component of EMO means embracing the initiation and implementation activities involved in e-marketing adoption. The initiation stage takes emarketing ideas and converts them into planned projects, whereas the implementation stage includes the activities involved in putting e-marketing to practical use (e.g. employing staff, buying and installing technologies).

Identifying the nature and components of EMO is important to understand the extent of emarketing adoption; what would enhance this understanding is the identification of the factors that may shape SMEs' EMO and consequently their involvement in e-marketing. The extant literature which discussed e-marketing enabling technologies adoption by SMEs is fragmented and fails to provide an understanding of what determines adoption (Simmons et al., 2011). Previous studies have generally focused on investigating the impact of selected variables on specific technologies. These variables were directly or indirectly inspired by innovation theories, particularly Tornatzky and Fleischer's (1990) context of technological innovation where they suggest that there are three interconnected elements of organizations' context that influence the adoption and implementation of technological innovations. These are the organizational, environmental and technological contexts. Another important element is the attributes suggested by the seminal Diffusion of Innovation theory (Rogers 1995), which identifies the determinants of the rate of innovation adoption; these include relative advantage, compatibility, complexity, trialability and observability. Example of studies that employed the context of technological innovation and Rogers' theory include Tan et al. (2009) who found that relative advantage, compatibility, complexity, observability, and security are significant factors influencing internet-based ICT adoption. Mehrtens et al. (2001) suggested that SMEs' decision to adopt the Internet is influenced by three groups of factors: perceived benefits, organizational readiness and external pressure, but found little evidence to suggest the adoption was influenced by external pressure. These studies have made a significant contribution to the field. However, little effort was found to examine the 
impact of the above mentioned variables from an organizational orientation perspective, although this should provide better understanding of the dynamics associated with e-marketing adoption since it explains which factors affect SMEs behaviors and philosophies towards e-marketing. Also, the EMO approach can be generalized to a wide range of e-marketing enabling technologies and applications since its focus is mainly on the organization rather than the technology itself.

\section{A structural model of EMO and its antecedents}

As stated earlier, EMO was conceptualized and validated as a multidimensional construct. Based on the conceptualization of EMO discussed earlier (see Shaltoni and west 2010 for details), EMO can be theoretically considered as high order formative because any changes in its components (philosophy and behavior) are expected to cause changes in its structure and dynamics. For example, if the SME owner is not convinced that social media is important for building their brand equity, they will not support activities that will enhance their social media presence, even if they have capable staff and established procedures/system for carrying out marketing activities. Accordingly, the following hypothesis is proposed:

H1: EMO is a second order formative construct that consists of three first order reflective indicators, which are management beliefs about e-marketing, initiation and implementation activities.

The antecedents of EMO were investigated to further validate the EMO construct. Investigating the effect of these factors, which have been identified from the literature, will lead to a comprehensive view on how to advise SMEs to further improve their e-marketing practices. Based on Tornatzky and Fleischer's (1990) context of technological innovation and Rogers' diffusion of innovation theory (1995), the following factors will be investigated:

- Perceived relative advantage is the degree to which an innovation is perceived as better than the idea it supersedes (Rogers 1995). The implication is that SMEs are more likely to be oriented towards e-marketing if they perceive that its enabling technologies provide greater benefits than existing methods. Thus:

$\mathrm{H} 2$ : There is a positive link between the perceived relative advantage of e-marketing and EMO in SMEs.

- Perceived complexity refers to an innovation being perceived as relatively difficult to understand and use (Rogers 1995). Complex technologies create greater uncertainty about their successful implementation; therefore, increasing the risks inherent in the decision to adopt them. Thus:

H3: There is a negative link between the perceived complexity of e-marketing and EMO in SMEs. 
- Compatibility refers to the degree to which an innovation is perceived as being consistent with existing values, past experience and the needs of potential adopters (Rogers 1995). The adoption of e-marketing resources can bring about significant changes to work practices, and consequently causes resistance, particularly if e-marketing requires radical changes in SMEs. Thus:

H4: There is a positive link between the perceived compatibility of e-marketing and EMO in SMEs.

- Competition is generally perceived to positively influence the adoption of innovations. Moreover, when the level of competition is high, organizations may adopt e-marketing not on account of its relative advantage, but on account of the competitors who have already adopted it. Thus:

H5: There is a positive link between the level of competition and EMO in SMEs.

- Finally, the requirements of customers represent a major force on SMEs. Indeed it is widely acknowledged that the Internet and other related technologies are creating powerful customer who have a wealth of accurate, updated and unbiased information (Pitt et al., 2002). Therefore, it is expected that SMEs will have higher levels of EMO if their customers exercise substantial pressure on them to be highly involved in e-marketing. Thus:

H6: There is a positive link between customer pressure to adopt e-marketing and EMO in SMEs.

\section{Methodology}

Given the lack of evidence on the topic, data were collected from SMEs in contrasting sectors and cross-nationally to assess the influence of overall economic development. The European commission definition of an SME being less than 250 employees was adopted. 650 SMEs were randomly selected from European directories that provided details about the number of employees. All study scales have been utilized and validated in prior research. Marketing managers were selected as the key informants for firms with more than ten employees. With micro companies (less than ten employees), general managers or owners were considered suitable informants given they are normally responsible for marketing decisions in general, and e-marketing decisions in particular. The constructs were measured using multi-item indicators to capture the underlying theoretical domains. Questionnaire were e-mailed to respondents and 136 responses were received, representing a response rate of 20 per cent. A Chi-square test was conducted to compare early and late respondents on demographic characteristics and EMO. The results revealed no significant differences $(p>.05)$ between the early and late respondents on the tested variables, which imply that non-response bias is not a problem in this study. PLS path modelling was used to analyze the relationships and test hypotheses. 


\section{Findings and conclusions}

The results (figure 1) confirmed that EMO is a second order formative construct that consists of three first order reflective indicator, namely: management beliefs about e-marketing (philosophical component), initiation and implementation activities (behavioral components). Table 1 shows that the correlations among the three constructs of EMO ranged from 0.382 to 0.635 and all correlations were significant at 0.01 level. In addition, each of the three constructs was also highly correlated ( 0.773 and above) with the overall measure of EMO and all correlations were significant at 0.01 level. In terms of multicollinearity among the three constructs of EMO, the table shows that the highest value of VIF was 1.708 for Philosophical component which is far below the common cut-off point threshold of 5. This suggests that multicollinearity is not an issue. However, regarding the last criterion i.e. formative outer weight, the table also shows that the path coefficients between the three constructs and EMO were all significant at 0.01 level. The results (figure 2) also showed that a statistically significant and positive relationship existed between EMO and perceived relative advantage, perceived compatibility, customer pressure and level of competition. Unexpectedly, no significant relationship was found between EMO and perceived complexity. One explanation for the result might be that organizational adoption of Internet technologies can be relatively simple because the technological standards of the Internet are fairly easy to learn and use (Afuah and Tucci 2001).

To summarize, EMO has never been statistically validated as a high-order formative construct using structural equation modeling. This research shows that the identified three constructs should be modeled formatively towards the hierarchical construct. As the degree of the overall EMO competency results from the judgment of the three lower-order constructs, causality is seen to flow from the sub-constructs to the higher-order construct. Moreover, each low-order construct addresses distinct yet related content, so the dimensions are not interchangeable. The deletion of a dimension would in fact critically alter the domain of the overall EMO.

The managerial 'message' from the research is that SMEs do not see e-marketing as a complex IT issue. E-marketing oriented SMEs appreciate e-marketing role in improving their relations with customers and sustaining/developing their competitive positions. Having an innovative manager who values the relative advantages offered by e-marketing appears to be decisive for the development of EMO. Applying the EMO framework will enable managers to score their orientation towards e-marketing and identify the factors affecting their orientation and the often quick fixes for improvement. By making use of the EMO evaluation, they can take the necessary action to improve their orientation towards e-marketing, and consequently, their involvement in it.

\section{References}

Avlonitis, G., \& Gounaris P. (1999). Marketing orientation and its determinants: An empirical analysis. European Journal of Marketing 33(11): 1003-1037.

Afuah, A., \& Tucci, CL. (2001). Internet business models and strategies. Boston: McGraw Hill. Jaworski, BJ,. \& Kohli AK. (1993). Market orientation: Antecedents and consequences. Journal of Marketing 57(3), 53-70. 
Mehrtens J,. Cragg P,. \& Mills A. (2001). A model of internet adoption by SMEs. Information and management 39(3), 165-176.

Narver JC \& Slater SF (1990). The effect of marketing orientation on business profitability. Journal of Marketing 54(4), 20-35.

Pitt LF, Berthon PR, Watson RT, \& Zinkhan GM (2002). The Internet and the birth of real consumer power. Business Horizons 45(4), 7-14.

Rogers, E. (1995). Diffusion of innovation. New York: The free press.

Shaltoni, AM,. \& West, DC. (2010). The measurement of e-marketing orientation (EMO) in business-to-business markets. Industrial Marketing Management 39(7), 1097-1102

Simmons, G,. Armstrong. GA,. \& Durkin MG. (2011). An exploration of small business Website optimization: Enablers, influencers and an assessment approach International Small Business Journal 29(5), 534-561

Tan KS,. Chong SC,. Lin B \& Eze UC. (2009). Internet-based ICT adoption: evidence from Malaysian SMEs. Industrial Management and Data Systems, 109(2), 224-244.

Tornatzky LG \& Fleischer M. (1990). The process of technological innovation. Massachusetts: Lexington Books.

\section{$\underline{\text { Tables/figures }}$}

Table 1

\begin{tabular}{|l|r|r|r|r|r|r|r|l|l|}
\hline \multicolumn{4}{|c|}{ External Validity } & \multicolumn{1}{c|}{ Multicollinearity } & \multicolumn{4}{c|}{ Formative Outer Weight } \\
\hline & Phil & Init & Impl & EMO & Tolerance & VIF & Direction & Path coefficient & t-value \\
\hline Phil & 1 & & & & .585 & 1.708 & Phil $\rightarrow$ EMO & 0.416 & 27.528 \\
\hline Init & $.382^{* *}$ & 1 & & & .803 & 1.245 & Init $\rightarrow$ EMO & 0.405 & 24.654 \\
\hline Impl & $.635^{* *}$ & $.428^{* *}$ & 1 & $*^{* *}$ & .551 & 1.814 & Impl $\rightarrow$ EMO & 0.402 & 27.712 \\
\hline EMO & $.798^{* *}$ & $.773^{* *}$ & $.845^{* *}$ & 1 & & & & & \\
\hline
\end{tabular}




\section{Figure1}

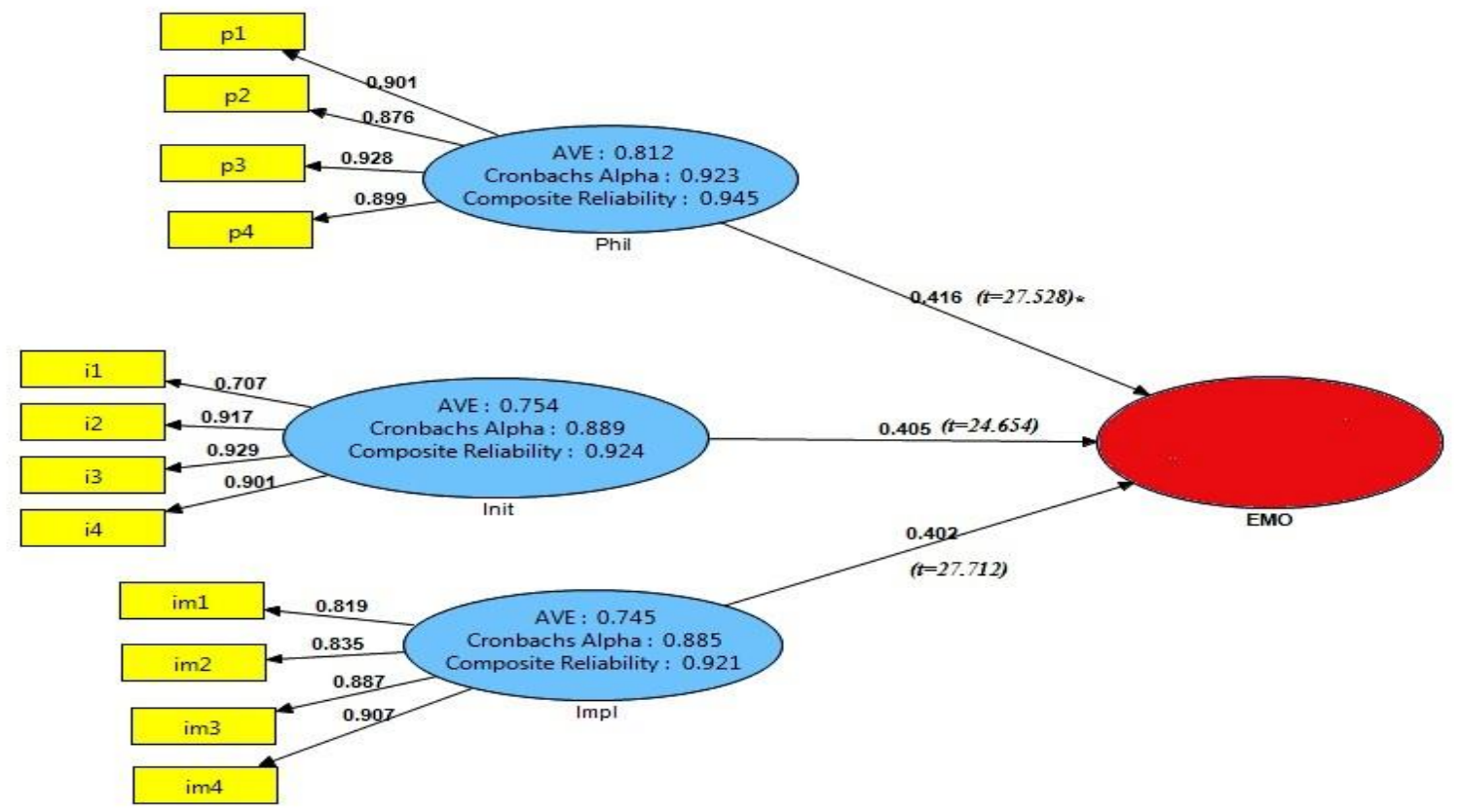

\section{Figure 2}
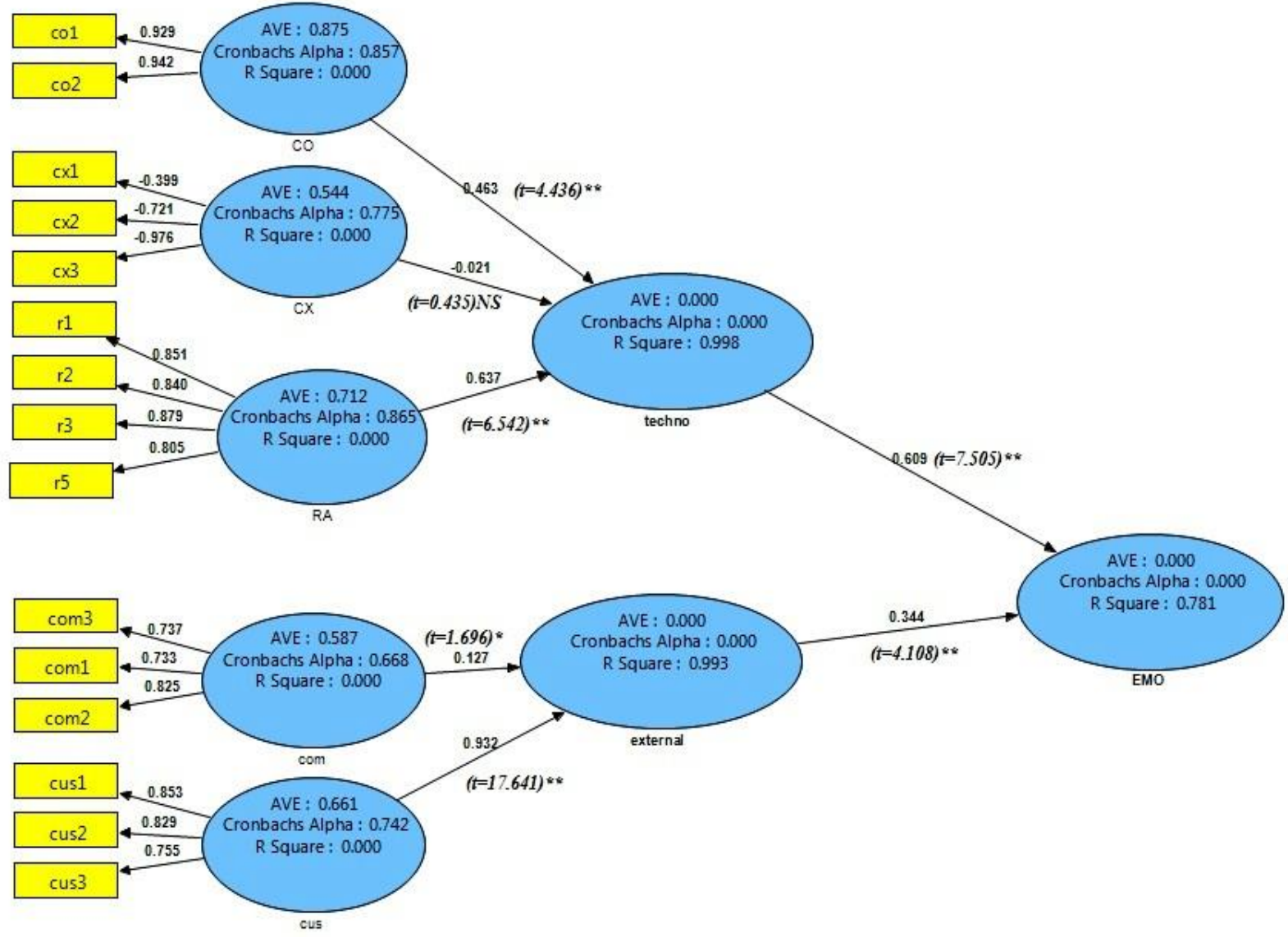